\title{
Statistical seismology: preface to the topical issue
}

\author{
Rodolfo Console $^{1,2}$ - Vassilios G. Karakostas ${ }^{3}$ Eleftheria E. Papadimitriou ${ }^{3}$. \\ Georgios M. Tsaklidis ${ }^{4}$
}

Received: 16 May 2017/Accepted: 16 May 2017/Published online: 29 May 2017

(C) Institute of Geophysics, Polish Academy of Sciences \& Polish Academy of Sciences 2017

From the Editors,

It is widely recognized that Seismology, the quantitative study of which started in the 19th century, has not yet achieved the ambitious target of predicting time, place and intensity of strong earthquakes in such a way as to allow concrete actions to mitigate their disastrous effects. This is mainly due to the intrinsic non-linear and chaotic nature of the earthquake process. In lack of any kind of physicsbased and deterministic prediction, seismologists have applied statistical models for seismic hazard assessment that could be useful for earthquake mitigation measures of prevention.

A special session on Statistical Seismology was organized in the program of the Fourteenth International Congress of the Geological Society of Greece, held at the Aristotle University Campus of Thessaloniki, Greece on 25-27 May 2016. The aim of this session was to bring together and foster collaboration among seismologists and

Rodolfo Console

r.console@cgiam.org; rodolfo.console@ingv.it

Vassilios G. Karakostas

vkarak@geo.auth.gr

Eleftheria E. Papadimitriou

ritsa@geo.auth.gr

Georgios M. Tsaklidis

tsaklidi@math.auth.gr

1 Center of Integrated Geomorfology for the Mediterranean Area, Potenza, Italy

2 Istituto Nazionale di Geofisica e Vulcanologia, Rome, Italy

3 Department of Geophysics, School of Geology, University of Thessaloniki, Thessaloniki, Greece

4 School of Mathematics, University of Thessaloniki, Thessaloniki, Greece mathematicians in order to reduce the gap that may exist between their different methodologies. In the course of this special session it was decided for a topical issue to be published where the presentations would be put together. Invitation was also extended to colleagues dealing with and interested in statistical seismology aspects.

The contributions cover a broad range of approaches to the study of non-randomness of the seismic processes.

One of these contributions (Abe and Suzuki) reports a comparative study on volcanic seismicity at Icelandic volcano, Eyjafjallajökull, and Mt. Etna in Sicily from the viewpoint of complex systems science, and discovers remarkable similarities between them.

Two papers (Leptokaropoulos et al., Olszewska et al.) consider time-dependent seismic hazard and other statistical features of mining-induced seismic events, a problem of great concern for mining industry in Poland.

The Group of the Geophysics Department of the University of Thessaloniki has provided three papers dealing with three different kinds of statistical analysis of seismicity in Central Ionian Islands and Corinth Gulf. They adopted respectively the Linked Stress Release Model (Mangira et al.), the Semi-Markov Model (Pertsinidou et al.) and the Complex Network Theory (Chorozoglou et al.).

Papadakis and Vallianatos have applied a non-extensive statistical physics analysis to the study of earthquake magnitude sequences in North Aegean Trough, Greece.

Different methods of modeling seismic processes applied to different countries are introduced by Gospodinov for the spatio-temporal evolution of aftershock energy release in California, and by Console et al. with a physicsbased earthquake simulator and applied to seismic hazard assessment in Calabria, Southern Italy. 